\title{
Eco-friendly technology of manufacturing complex products made of composites
}

\author{
Aleksey Ignatov ${ }^{1}$, and Rustam Subkhankulov ${ }^{1, *}$ \\ ${ }^{1}$ Bauman Moscow State Technical University, Moscow, Russian Federation
}

\begin{abstract}
Numerous studies in application of modern composite materials show that their advantages can be successfully implemented in manufacturing «smart» products. This study proposes an improved technological method of manufacturing multilayer environmentally friendly products with a variable cross section, which allows us to expand the possibilities of using modern polymer composite materials (PCM). The technology allows manufacturing products of the most complex geometric shapes, such as wind turbine blades. The aim of the study is the technological support of engineering production in the manufacture of multilayer products of variable cross section made from PCM. Scientific novelty consists in identifying the patterns of implementation and management of the manufacturing process of multilayer products of variable cross-section, and establishing the influence of structural and technological parameters of the manufacturing process on their operational characteristics. The relationship between the pressure of a hot directed air stream and the volume fraction of pores in the hardened material of a multilayer composite product with a variable cross section during layer-by-layer application is investigated. During the study, fundamental and applied principles of mechanical engineering technology, material resistance, adhesion theory, mathematical statistics tools and software were used to process the results of the experiment. Based on the results of laboratory studies, a methodology has been developed for effective prediction of pore content in the manufacturing of composite products. The introduction of the presented technology and the corresponding original methodology into production will reduce the complexity and energy costs of manufacturing composite products, improve their quality and reduce the impact of toxic components from composite materials on workers.
\end{abstract}

\section{Introduction}

Qualitative transition from research to study the possibilities for the use of artificially created multicomponent materials to high efficient technical process of serial production of devices from it formed and developed in modern high technology production. Numerous studies in the application of modern PCM show that their advantages can be successfully implement in the manufacture of «smart» designs [1].

Such eco-friendly devices made of PCM include blades of wind turbines, helicopters blades, turbines blades, corps, power components and other. These devices have high indexes of strength, resources, reliability and weight quality exceeding the corresponding indexes of tools made from famous natural materials. Main feature of constructional materials received by adhesive composition of continuous reinforcing threads of glass, coal, boron and other fibers is profitably use during their manufacture [2]. This feature is the possibility of manufacture of devices with pre-known properties most fully relevant to functioning and working conditions.
Technological processes of manufacture of mentioned devices, despite their constructional differences, have similar structure and contain two basic and interrelated stages [3]. At the first stage, multilayer workpiece is assembled using forming arbor closed in form to the finished device. Predetermined composition, configuration and stacking direction of each layer of multilayer structure are provided during assembly. At the second stage, modeling of previously obtained workpiece is produced using chosen technological method. At the same time, solidification of polymer matrix of device is provided forming its geometrical dimensions and spatial configuration $[4,5]$.

Structure analysis of labor content of PCM devices indicates that biggest part of labor cost spends at the stage of multilayer workpiece assembly [6]. It is because multilayer workpiece assembly is handmade in more than 95 percent of cases in modern industry $[7,8]$. Numerous attempts to mechanize and automatize process of multilayer workpiece assembly were made at the second half of last century, but highly productive equipment for adhesive assembly is still not widely used due to limited technological capabilities [9]. Wider use

\footnotetext{
* Corresponding author: subtem@rambler.ru
} 
of modern composite materials in aerospace and aviation industry is constrained by lack of technologies and corresponding equipment for automated assembly of devices, which allows to get profiles of spatially complex configuration [10,11].

Highly productive complexes for winding and automated laying out using special head section with pressure roller are not efficient due to their significant technical limitation for made profiles. It is possible to obtain only profiles close to the circle in winding. It is impossible to obtain rounding and small radius curvatures using inflexible roller during laying out [12]. Besides, contact type of laying out process of profile devices for aerospace and aviation industry requires long and toilful selection of processing methods, preparations and debugging of control program due to necessity to ensure complex cinematics, the use of extremely highquality materials [13, 14, 15].

Technological solutions for changing contact process of laying out a pre-impregnated reinforcing fiber are in demand in modern high technology machine engineering. Development of noncontact methods of laying out is becoming crucial task $[15,16]$. Complexes for noncontact laying out do not exist in modern industry.

Authors develop noncontact adhesive assembly of multilayer devices using directional hot air flow in making polymer devices with variable cross section in order to technological support for industry. Processing method will allow to avoid disadvantages of existing methods, to improve quality of produced devices, to increase productivity. It consists in the use of hot air from nozzles during application of pre-impregnate reinforcing fiber on the arbor forming future device. The process is the flow of adhesive composition along complex surface of forming arbor (fig. 1). Activation and flow control are carried out by combining of forming movement of nozzles and selection of corresponding technological modes. Nozzles can specify required technological modes on temperature and the air pressure. Possibility to control modes according to temperature and the air pressure allows to create favorable conditions for snug fit of reinforcing material on complex surface of arbor. The method enables to automatize process of production of complex profile devices without using complex cinematic.

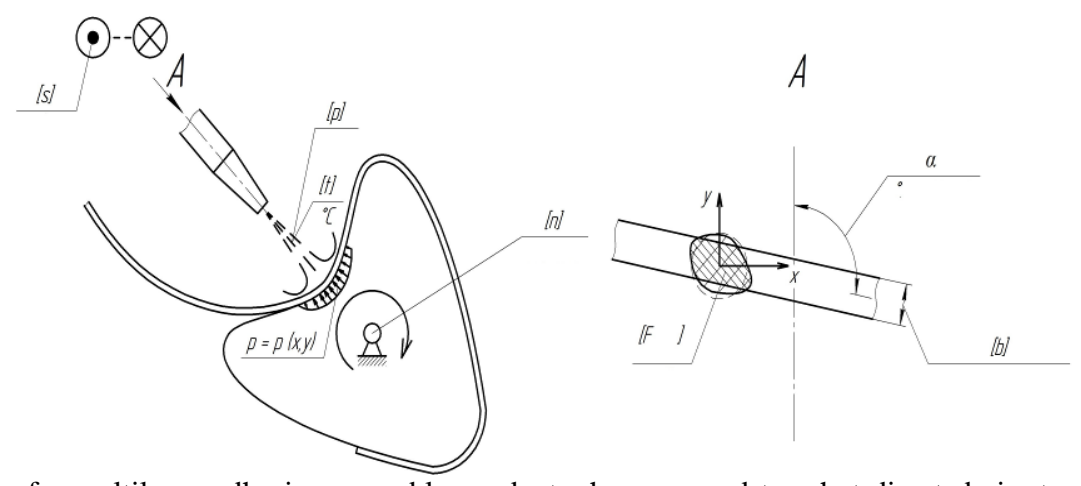

Fig. 1. The formation of a multilayer adhesive assembly product when exposed to a hot directed air stream and the technological conditions provided

Developed method is patented. It has no analogues in the world. It is domestic product. The method is based on the use of domestic materials and components. Practical researches of possibilities of the method are conducting using experimental apparatus nowadays.

The purpose of the study is the technological support of engineering production in the manufacture of composite multi-layer products of variable cross section.

The main objectives of the study:

1. Development and research of a method for manufacturing composite multilayer products of variable cross section.

2. Technological development of designs of adjustable multilayer products of variable cross section.

3. Development of methods for manufacturing composite multilayer products of variable cross section.

4. The study of technical and operational indicators of composite multilayer products of variable cross section.

Scientific novelty consists in identifying patterns of implementation and process control of manufacturing multi-layer products of variable cross-section, establishing the influence of design and technological parameters of the process on the operational characteristics of multi-layer products of variable crosssection.

The practical significance of the work lies in the proposal of a technological method for manufacturing composite multilayer products of variable cross-section, the development of a methodology for controlling the characteristics of the technological method, the development of standard equipment for the technological method.

\section{Methods}

Structural porosity is one of the main qualitative characteristics of multilayer devices of adhesive assembly with variable cross section $[17,18]$. Porosity determines presence of the air inclusions in multilayer structure of material, therefore, directly affects its strength and other operational properties [19, 20]. Ensuring the least pore volume fraction is important 
characteristic of possibilities of the technological method during production of multilayer devices [21, 22].

Sequential air displacement from interfibre space and uniform distribution of liquid adhesive composition along materials surface occurs due to effect of directional hot air flow. Intensity of processes of adhesive composition distribution and displacement of air inclusions depends from viscosity of adhesive composition and pressure of directional hot air flow.

Studies were conducted using a special installation (fig. 2).
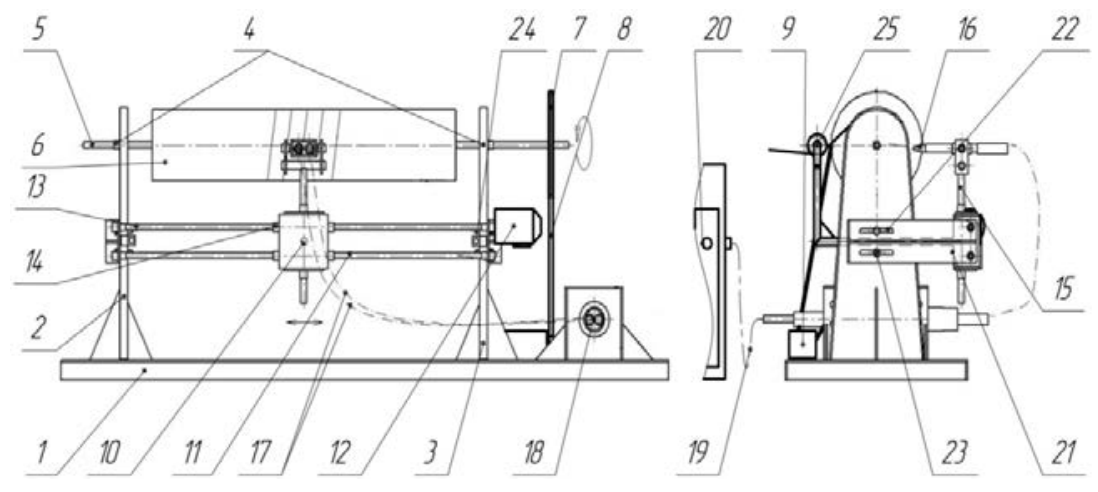

Fig. 2. The experimental installation: 1 - base; 2, 3 - racks; 4 - supports; 5 - shaft; 6 - shaping mandrel; 7 - a pulley; 8 - belt; 9,12 electric motor; 10 - carriage; 11 - a guide; 13 - lead screw; 14 - a nut; 15 - rack; 16 - air nozzle; 17, 19 - air duct (hose); 18 - air heater; 20 - compressor; 21 - an arm; 22 - grooves; 23 - bolts; 24 - switches; 25 - a directing roller; 26 - stand

Laboratory studies, held by the authors, confirmed interrelation between pressure of directional hot air flow and pore volume fraction in solidified material of multilayer device of adhesive assembly with variable cross section during layer-by-layer application. Method of efficient control of porosity during adhesive assembly of devices is developed on the basis of results of laboratory studies.

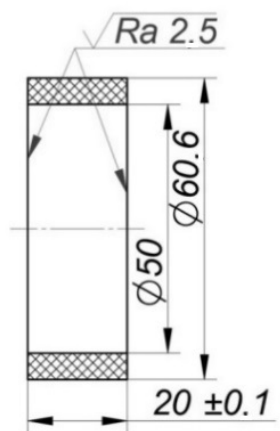

Fig. 3. Sample of multilayer device of adhesive assembly.

Six samples of multilayer devices of adhesive assembly, which are smooth bushings of 20 layers of fabric T-10-14 GOST 19170-2001 impregnated with adhesive composition EDT-10, were produced for experimental research. Fig. 3 shows the schematic drawing. Forming of multilayer workpiece for samples was produced on arbor with circular cross section $50 \mathrm{~mm}$ in diameter using experimental apparatus with different modes for each sample according to pressure of directional hot air flow.

\section{Results and Discussion}

Sequential weighting of samples was conducted after their solidified in the air or in 95 percent solution of ethyl alcohol of technical grade A GOST 17299-78. Electronic dynamometer of grade ACDR-0.1 I-1 TU 4273-023-67392736-2011 with 0.1 g scale division was used in the weighting. Table 1 shows the results of the weighting.

Table 1. Results of sample's weighting of multilayer devices of adhesive assembly.

\begin{tabular}{|c|c|c|c|c|}
\hline $\begin{array}{c}\text { Sample' } \\
\text { s } \\
\begin{array}{c}\text { sequenc } \\
\text { e } \\
\text { number }\end{array}\end{array}$ & $\begin{array}{c}\text { Pressure } \\
\text { of } \\
\text { directiona } \\
\text { l air flow } \\
\text { from } \\
\text { nozzle, } \\
\text { MPa }\end{array}$ & $\begin{array}{c}\text { Sample' } \\
\text { s mass } \\
\text { in the } \\
\text { air, g }\end{array}$ & $\begin{array}{c}\text { Sample' } \\
\text { s mass } \\
\text { in } \\
\text { ethanol, } \\
\text { g }\end{array}$ & $\begin{array}{c}\text { Relative } \\
\text { porosity } \\
\text {, }\end{array}$ \\
\hline 1 & 0.17 & 68.5 & 22.7 & \\
\hline 2 & 0.2 & 68.5 & 22.8 & 2.8 \\
\hline 3 & 0.23 & 68.5 & 23.5 & 1.3 \\
\hline 4 & 0.25 & 68.5 & 23.8 & 0.72 \\
\hline 5 & 0.28 & 68.5 & 23.4 & 1.5 \\
\hline 6 & 0.3 & 68.5 & 23.2 & 1.9 \\
\hline
\end{tabular}

Interrelation between relative porosity of multilayer devices of adhesive assembly and pressure of directional hot air flow has been established as a result of experimental research (Fig. 4). 


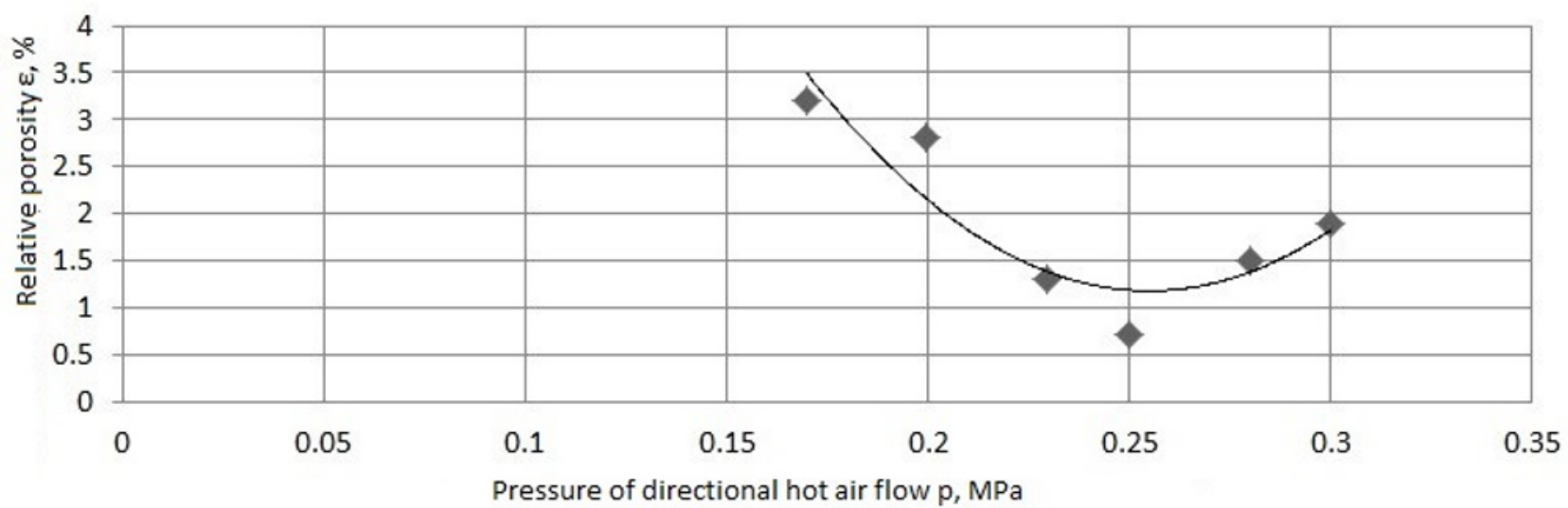

Fig. 4. Dependency graph of sample’s relative porosity from pressure of directional hot air flow

Fig. 4 experimentally shows that relative porosity decreases to the minimum value of 0.72 percent during an increase of pressure of directional hot air flow. Relative porosity begins to increase rapidly when the pressure increases further.

The results of the experiment are explained by controlled decrease of porosity, snug fit of reinforcing material, displacement of air bubbles from interfibre space, disposal of surplus of adhesive composition due to air flow effect. It is shown that the pressure change in the range of $0.2 \ldots 0.3 \mathrm{MPa}$ does not have significant impact on quality of produced device, therefore, complex cinematic is not required in implementing the method.

It is important that obtained the value of the relative porosity of 0.72 percent indicates high results characterizing possibilities of the technological method for production of critical devices. Relative porosity of devices reaches 0.5-5.5 percent depending on using method in modern machine engineering $[23,24]$.

Results of the experiment were processed using the Mathcad software. The empirical dependence was received:

$$
\varepsilon=319.85 p^{2}-163.16 p+21.988
$$

where $\varepsilon$ is the relative porosity; $p$ is pressure of directional air flow, MPa.

Revealed dependence allows to forecast pore volume fraction in device and to control it efficiently during production.

\section{Conclusions}

The presented research results demonstrate possibilities of using the technological method during automated production of the most critical complex profile devices for aerospace and aviation industry. Further development and subsequent implementation of the technological method will significantly increase opportunities to use modern PCM, to reduce labor content, to increase stability of qualitative characteristics of devices due to automatization of the most critical technological processes of adhesive assembly during production of devices.
The results of the study were partially obtained and applied in the implementation of the scientific project under the contract No. 14766GU / 2019 dated 05.08.2019. Ground: Decision of the tender committee of the Innovation Assistance Fund, protocol of the meeting of the Directorate No. 6 on approval of the results of the competitive selection under the UMNIK program of 19.04.2019.

\section{References}

1. B. Denkena, C. Schmidt, P. Weber, Proc. Manufact. J. 6, 96 (2016)

2. M. Gorodetskii, V. Nelyub, G. Malysheva, A. Shaulov, A. Berlin, Rus. Metal. J. 13, 1195 (2018)

3. K. Croft, L. Lessard, D. Pasini, M. Hojjati, J. Chen, A. Yousefpour, Appl. Scien. and Manufact. J. 42, 484 (2011)

4. A. Kharaev, R. Bazheva, M. Begieva, V. Nelyub, A. Borodulin, Polym. Scien. J. 12, 24 (2019)

5. M. Nik, K. Fayazbakhsh, D. Pasini, L. Lessard, Comp. Struct. J. 107, 160 (2014)

6. A. Bocharov, V. Vigovskiy, V. Nelyub, Materials Today: Proceedings 11, 107 (2019)

7. R. Harik, C. Saidy, S. J. Williams, Z. Gurdal, B. Grimsley, SAMPE Conference Proceedings (2018)

8. A. Azeez, K. Rhee, S. Park, D. Hui, Engineer. J. 45, 308 (2013)

9. T. Burchenkova, V. Slavkina, V. Nelyub, Materials Today: Proceedings 11, 112 (2019)

10. R. Rizzolo, D. Walczyk, J. of Therm. Comp. Mat. 29, 1480 (2016)

11. A. Aziz, M. Ali, X. Zeng, R. Umer, P. Schubel, W. Cantwell, Comp. Scien. and Techn. J. 152, 57 (2017)

12. V. Nelyub, B. Gorberg, M. Grishin, S. Sarvadii, B. Shub, A. Berlin, G. Malysheva, Fibre Chem. J. 50, 524 (2019)

13. O. Rimmel, D. May, C. Goergen, A. Poeppel, P. Mitschang, J. Comp. Mat. 53, 3257 (2019)

14. E. Zympeloudis, K. Potter, P. Weaver, B. Kim, 21st International Conference on Composites Materials (2017)

15. A. Borodulin, A. Kalinnikov, A. Kharaev, S. Shcherbin, IOP Conference Series: Earth and Environmental Science 302, (2019) 
16. C. Stokes-Griffin, P. Compston, Appl. Scien. and Manuf. J. 75, 104 (2015)

17. A. Borodulin, A. Kalinnikov, A. Tereshkov, A. Kharaev, Materials Today: Proceedings 11, 139 (2019)

18. A. Comer, D. Ray, W. Obande, D. Jones, J. Lyons, I. Rosca, M. McCarthy, Appl. Scien. and Manufact. J. 69, 10 (2015)

19. F. Shadmehri, O. Ioachim, O. Pahud, J. Brunel, A. Landry, V. Hoa, M. Ho-jjati, 20th International Conference on Composite Materials, (2015)

20. A. Kharaev, R. Bazheva, M. Begieva, V. Nelyub, A. Borodulin, Polym. Scien. J. 12, 24 (2019)

21. E. Oromiehie, B. G. Prusty, P. Compston, G. Rajan, Struct. Heal. Monit. J. 17, 108 (2018)

22. V. Nelyub, A. Borodulin, Polym. Scien. J. 11, 147 (2018)

23. V. Tarasov, M. Komkov, V. Romanenkov, R. Boyarskaya, D. Boyarskii, Polym. Scien. J. 11, 179 (2018)

24. V. Tarasov, M. Komkov, V. Romanenkov, A. Alyamovsky, N. Kopyl, R. Boyarskaya, IOP Conference Series: Materials Science and Engineering, 153, (2016) 